International Journal of Medical Anesthesiology 2020; 3(1):172-176

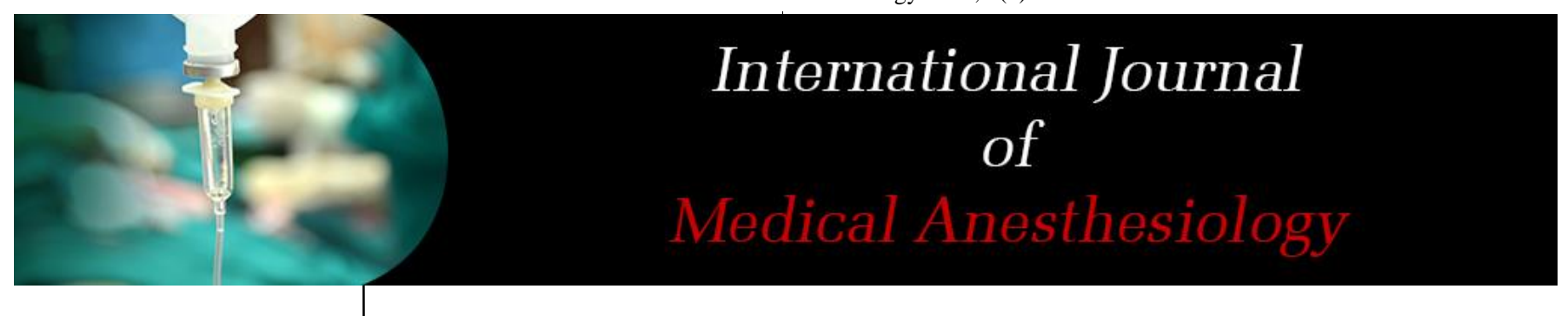

E-ISSN: 2664-3774

P-ISSN: 2664-3766

www.anesthesiologypaper.com

IJMA 2020; 3(1): 172-176

Received: 13-11-2019

Accepted: 17-12-2019

Dr. Kuppannagari Subba

Reddy

Assistant Professor,

Department of

Anaesthesiology, S.V.S

Medical College,

Mahabubnagar, Telangana,

India

Dr. Spoorthy Uppuleti

Assistant Professor,

Department of

Anaesthesiology, Chalmeda

Ananda Rao Institute of

Medical Sciences, Karimnagar,

Telangana, India
Corresponding Author: Dr. Spoorthy Uppuleti Assistant Professor,

Department of Anaesthesiology, Chalmeda Ananda Rao Institute of Medical Sciences, Karimnagar, Telangana, India

\section{A study on compare the efficacy of injection Ondansetron intravenous versus injection ondansetron plus injection Dexamethasone intravenous combination in prevention or reduction of Postoperative nausea and vomiting after elective surgeries under general anaesthesia}

\section{Dr. Kuppannagari Subba Reddy and Dr. Spoorthy Uppuleti}

DOI: https://doi.org/10.33545/26643766.2020.v3.i1c.86

\begin{abstract}
Background: PONV has been recognized as one of the major complications after elective surgeries under general anesthesia. The incidence of PONV can be as frequent as $70 \%$ to $80 \%$ in high risk groups, so prevention or reduction of PONV remains one of the major goals to be achieved.

Aim \& objective: The objective of this study is to compare the efficacy of intravenous ondansetron versus intravenous ondansetron plus dexamethasone combination in prevention / reduction of PONV after elective surgeries under general anesthesia with respect to early and delayed vomiting and their side effects.

Methods: Our study was done in 100 patients, randomly divided into 2 groups of 50 patients each. One group received intravenous ondansetron $4 \mathrm{mg}$ while the other group received intravenous ondansetron $4 \mathrm{mg}$ plus dexamethasone $8 \mathrm{mg} 30$ seconds before induction. Postoperatively patients were assessed hourly for 4 hours and then at 24 hours for degree of nausea, retching and vomiting, requirement of rescue antiemetic and side effects. Vomiting occurring upto 4 hours was considered as early and from 4-24 hours, as delayed vomiting.

Results: Incidence of early and delayed nausea (20\% each) was less in the combination group compared to ondansetron alone. Delayed vomiting was lower in the combination group compared to ondansetron alone.

Conclusion: We hereby conclude that combination therapy of ondansetron and dexamethasone is superior and cost-effective in controlling PONV with delayed PONV being better controlled than early PONV compared to ondansetron alone.
\end{abstract}

Keywords: Nausea; vomiting; early; delayed; ondansetron; dexamethasone; general surgery

\section{Introduction}

Postoperative nausea and vomiting are frequent and well recognized unpleasant complications following anaesthesia and surgery. First extensive description was given by John Snow, published in 1848. During the past decade, much effort has been placed correctly on ensuring patients' adequate pain relief after surgery. However, PONV are still viewed as minor problems by some physicians, even though they are leading causes of morbidity in paediatric surgical patients ${ }^{[1]}$.

Inspite of the advances using less emetic anaesthetic agents, improved pre and post-operative medication, refinement of operative technique and identification of patient predictive factors, nausea and vomiting still occur with unacceptable frequency in association and is described as the "big little problem" [2].

Early studies reported incidence of postoperative nausea and vomiting as high as 75-80\% after opioid premedication and prolonged Ether anaesthesia. But in the second half of this century, however these incidences have decreased by almost $50 \%$ for various reasons ${ }^{[3]}$.

Persisting PONV is very much distressing and debilitating to the patient and can cause many complications to the patients like esophageal tears, gastric herniation, muscular strain and fatigue ${ }^{[4]}$. The increase in intracranial pressure and intraocular pressure may even cause blindness ${ }^{[5]}$.

The fluid and electrolyte loss accompanying vomiting may lead to dehydration and lifethreatening electrolyte imbalance. ${ }^{5}$ In addition, it also increases the risk of pulmonary 
aspiration [4]. Most important of all, PONV may have psychologic impact on the patient and it may be so severe as to cause aversion towards surgery. In a survey of ambulatory patients who were dissatisfied with the outcome of their operations, $71 \%$ cited PONV as the reason ${ }^{[5]}$.

Antiemetic drugs play an important role in the therapy of PONV. Though many drugs have been tried in the prophylaxis and treatment of PONV, no drug has been proved significantly effective and a search for a better drug continues.

The present study was designed to study the efficacy of ondansetron versus ondansetron and dexamethasone combination in the prevention and or reduction of PONV after elective surgeries under general anaesthesia.

The aim of this study is to compare the efficacy of injection ondansetron intravenous versus injection ondansetron plus injection dexamethasone intravenous combination in prevention or reduction of PONV after elective surgeries under general anaesthesia with respect to Early vomiting, Delayed vomiting and Side effects.

\section{Materials and methods}

The present study was conducted in 200 adult patients undergoing elective surgeries under general anaesthesia in Prathima Medical College \% Hospital, Karimnagar, Telangana India during the period 20018-2019.

After institutional committee approval and written informed consent, patients posted for various surgeries requiring general anaesthesia were selected.

The study population was divided into 2 groups of 50 patients each.

Group A: Group which received injection ondansetron 4 mg intravenously.

Group B: Group which received injection ondansetron 4 $\mathrm{mg}$ and injection dexamethasone $8 \mathrm{mg}$ intravenously.

\section{Selection of patients inclusion criteria}

- Patients aged between 20-60 years.

- Patients belonging to ASA I and ASA II grade.

- Patients undergoing elective surgeries under general anaesthesia.

\section{Exclusion criteria}

- Renal impairment and hepatic disease

- Neurological and endocrinal abnormalities

- Pregnancy and lactation

- Patients with history of PONV in previous surgery

- Patient with history of motion sickness

- Patients with history of vomiting and Ryle's tube in situ in the past 24 hours.

\section{Methods \\ Preoperative evaluation}

Preoperative visit was conducted on the day before surgery. Detailed history of patient's complaints were noted. General and systemic examination of cardiovascular and respiratory systems were done.

Basic investigations like blood hemoglobin, total count and differential count, ESR, blood sugar estimation, blood urea and serum creatinine and urine screening for albumin, sugar and microscopy were done. Other investigations included ECG, chest x-ray, HIV and HbsAg.

\section{Preoperative order}

Patients were advised to remain nil orally after midnight and all of them received tablet diazepam $10 \mathrm{mg}$ orally on the night before surgery.

\section{Anaesthesia}

On the morning of surgery, no premedication was given. When the patient was brought to the operation theatre, his / her pulse rate and blood pressure were recorded. An i.v., access with an appropriate size cannula was obtained.

Injection ondansetron $4 \mathrm{mg}$ intravenously or injection ondansetron $4 \mathrm{mg}$ plus injection dexamethasone $8 \mathrm{mg}$ intravenously was given in group A and group B patients respectively 30 seconds prior to induction. This was followed by injection pentazocine $0.5 \mathrm{mg} / \mathrm{kg}$ i.v. as an analgesic.

After preoxygenation for 3 minutes, general anaesthesia was induced with injection thiopentone sodium (2.5\%) 3-5 $\mathrm{mg} / \mathrm{kg}$ i.v. along with injection atropine $0.02 \mathrm{mg} / \mathrm{kg}$ i.v. Relaxation was obtained by giving injection scoline $2 \mathrm{mg} / \mathrm{kg}$ i.v. and either nasotracheal intubation or orotracheal intubation with an appropriate sized cuffed portex tube was done.

Duration of surgery was noted. Patients were observed for 24 hours postoperatively. Nausea, retching and vomiting were recorded hourly for 4 hours and then at the end of 24 hours. Any other complications were also noted.

\section{Assessment}

The number of episodes of nausea, retching and vomiting were recorded. Each episode of emesis producing atleast 5 $\mathrm{ml}$ was recorded. Repeated vomiting within a 1- 2 minute period was recorded as a single emesis. The data were taken as follows

0 . None

1. Episode - Mild

2. Episodes - Moderate

3. Episodes - Severe

Similarly, the number of episodes of nausea and retching were also registered and the data recorded as follows-

0 . None

1. Episode-Mild

2. Episodes-Moderate

3. Episodes-Severe

Rescue antiemetic consisted of injection metoclopramide $0.15 \mathrm{mg} / \mathrm{kg}$ i.v. and was given for more than 2 episodes of vomiting.

\section{Statistical analysis}

The data are expressed as distribution of cases with corresponding number of episodes of nausea, retching, vomiting and need for rescue antiemetic. Study results were analyzed by student's " $t$ " test and categorical data was analyzed by chi-square test.

\section{Results}

Table 1: Age distribution of study Groups

\begin{tabular}{|c|c|c|}
\hline Age (Years) & Group A (\%) & Group B (\%) \\
\hline $20-29$ & $20(40)$ & $18(36)$ \\
\hline $30-39$ & $22(44)$ & $21(42)$ \\
\hline $40-49$ & $8(16)$ & $10(20)$ \\
\hline $50-59$ & 0 & $1(2)$ \\
\hline
\end{tabular}


100 patients were randomized into 2 groups of 50 patients each. The mean age in group A was $28.47 \pm 5.21$ years against $30.92 \pm 6.30$ years in group $B$. This was found to be statistically insignificant $(p>0.05)$.

Table 2: Sex distribution of study Groups

\begin{tabular}{|c|c|c|c|c|}
\hline Sex & Group A (\%) & Group B (\%) & P* Value & Significance \\
\hline Male & $30(60)$ & $28(56)$ & $\mathrm{P}=0.78$ & Not Significant \\
\hline Female & $20(40)$ & $22(44)$ & & \\
\hline
\end{tabular}

In the group A, among 50 patients 30 patient were male while 20 patients were female against 28 male and 22 female patients in group B. This was statistically insignificant $(p>0.05)$.

Table 3: Duration of surgery

\begin{tabular}{|c|c|c|c|c|}
\hline Study groups & Group A & Group B & P* Value & Significance \\
\hline Mean+/- SD & $50.55+/-23.47$ & $48.30+/-21.90$ & P $=0.48$ & Not Significant \\
\hline
\end{tabular}

The mean duration of surgery was $50.55 \pm 23.47$ minutes in group A and $48.30 \pm 21.90$ in group B. p value was insignificant.

Table 4: Types of surgeries performed

\begin{tabular}{|c|c|c|}
\hline Type of surgery & Group A & Group B \\
\hline Appendicectomy & 1 & 1 \\
\hline Dermoid excision & 1 & 4 \\
\hline Fibroadenoma excision & 3 & 1 \\
\hline Granuloma excision & 1 & 2 \\
\hline Hemithyroidectomy & 3 & 2 \\
\hline Humerus plate removal & 1 & 2 \\
\hline Keloid excision & 2 & 3 \\
\hline Lipoma excision & 4 & 2 \\
\hline Lymph node excision & 3 & 4 \\
\hline Mastoidectomy & 4 & 2 \\
\hline ORIF fracture both bone forearm & 2 & 1 \\
\hline Paraumbilical hernia repair & 2 & 1 \\
\hline Polypectomy & 2 & 5 \\
\hline Sebaceous cyst excision & 3 & 1 \\
\hline Septoplasty & 2 & 2 \\
\hline SMR & 2 & 2 \\
\hline SMR with Turbinectomy & 3 & 10 \\
\hline Thyroglossal cyst removal & 3 & 1 \\
\hline Tonsillectomy & 12 & \\
\hline
\end{tabular}

Patients in both groups were subjected to similar type of surgeries and they were comparable in all aspects. $\mathrm{p}$ value was found to be insignificant.

\section{Post-operative data}

Table 5: Nausea episodes

\begin{tabular}{|c|c|c|c|c|c|c|c|c|}
\hline & \multicolumn{2}{|c|}{ Early Nausea } & & & \multicolumn{2}{|c|}{ Delayed Nausea } & & \\
\hline & Group A (\%) & Group B (\%) & P* Value & Significance & Group A (\%) & Group B (\%) & P* Value & Significance \\
\hline No Episode & $22(44)$ & $40(80)$ & & & $30(60)$ & $36(72)$ & & \\
\hline Mild & $23(46)$ & $10(20)$ & $D<0 \Omega 01$ & Highly & $15(30)$ & $10(20)$ & $D<0$ & \\
\hline Moderate & $5(10)$ & 0 & $P<0.001$ & Significant & $5(10)$ & $4(8)$ & $P<0.01$ & ant \\
\hline Severe & 0 & 0 & & & 0 & 0 & & \\
\hline
\end{tabular}

* Chi Square Test

\section{Early nausea}

Incidence of early nausea was statistically highly significant $(p<0.001)$. 23 patients in group A had mild nausea compared to 10 patients in group B. 5 patients in group A had moderate nausea compared to no patients in group B. None of the patients in both groups had severe nausea.

\section{Delayed nausea}

In group A, 15 patients had mild episodes compared to 10 patients in group B. 5 patients in group A had moderate episodes compared to 4 episodes in group B. None of the patients had severe nausea. The difference between the groups was found to be statistically significant $(p<0.01)$.

Table 6: Retching episodes

\begin{tabular}{|c|c|c|c|c|c|c|c|c|}
\hline & \multicolumn{2}{|c|}{ Retching (Early) } & \multirow{2}{*}{ P* Value } & \multirow{2}{*}{ Significance } & \multicolumn{2}{|c|}{ Retching (Delayed) } & \multirow{2}{*}{ P* Value } & \multirow{2}{*}{ Significance } \\
\hline & Group A (\%) & Group B (\%) & & & Group A (\%) & Group B (\%) & & \\
\hline No Episode & $26(52)$ & $36(72)$ & \multirow{4}{*}{$P<0.01$} & \multirow{4}{*}{ Significant } & $37(74)$ & $49(98)$ & \multirow{4}{*}{$P<0.001$} & \multirow{4}{*}{ Highly Significant } \\
\hline Mild & $14(28)$ & $9(18)$ & & & $10(20)$ & $1(2)$ & & \\
\hline Moderate & $10(20)$ & $5(10)$ & & & $3(6)$ & 0 & & \\
\hline Severe & 0 & 0 & & & 0 & 0 & & \\
\hline
\end{tabular}




\section{Early retching}

14 patients in group A had mild episodes compared to 9 patients in group B while 10 patients in group A had moderate episodes compared to 5 patients in group B. None of the patients in both groups experienced severe episodes. Difference between the groups was found to be significant.

\section{Delayed retching}

10 patients in group A had mild episodes of retching compared to 1 patient in group B. Moderate episodes were observed in 3 patients of group A while no patient experienced in group B. None of the patients had severe episodes. The difference between the groups was found statistically to be highly significant.

Table 7: Vomiting episodes

\begin{tabular}{|c|c|c|c|c|c|c|c|c|}
\hline & \multicolumn{2}{|c|}{ Vomiting (Early) } & & & \multicolumn{2}{|c|}{ Vomiting (Delayed) } & & \\
\hline & Group A (\%) & Group B (\%) & P* Value & Significance & Group A (\%) & Group B (\%) & P* Value & Significance \\
\hline No Episode & $35(70)$ & $39(78)$ & & & $28(56)$ & $48(96)$ & & \\
\hline Mild & $10(20)$ & $10(20)$ & $P>005$ & Not Sianificant & $4(8)$ & 0 & $P<0001$ & Highly Sianificant \\
\hline Moderate & $2(4)$ & $1(2)$ & $P>0.05$ & Not Signiticant & $18(36)$ & $2(4)$ & $P<0.001$ & Higniy Signiricant \\
\hline Severe & $3(6)$ & 0 & & & 0 & 0 & & \\
\hline
\end{tabular}

\section{Early vomiting}

In group A, 10 patients experienced mild episodes compared to 10 patients in group B. 2 patients in group A had moderate episodes compared to 1 patient in group B. 4 patients in group A had severe episodes compared to none in group B. The difference between the groups was found to be not significant.

\section{Delayed vomiting}

4 patients of group A experienced milder episodes compared to none in group B. 18 patients in group A had moderate episodes compared to 2 patients in group B. None of the patients in both groups had severe episodes. The difference was found to be statistically significant.

Table 8: Rescue antiemetic

\begin{tabular}{|c|c|c|c|c|}
\hline & Group A (\%) & Group B (\%) & \multirow{2}{*}{ P* Value } & Significance \\
\hline Required & $14(28)$ & $2(4)$ & \multirow{2}{*}{$P<0.001$} & Highly \\
Not Required & $36(72)$ & $48(96)$ & Significant \\
\hline
\end{tabular}

Need for rescue antiemetic was found to be statistically significant. 36 patients in group A compared to 2 patients in group B needed rescue antiemetic.

Table 9: Side effects

\begin{tabular}{|c|c|c|c|c|}
\hline & Group A (\%) & Group B (\%) & P* Value & Significance \\
\hline Diarrhoea & $2(4)$ & $1(2)$ & $P>0.05$ & Not Significant \\
\hline Headache & $6(12)$ & $4(8)$ & & \\
\hline Flushing of face & 0 & $1(2)$ & & \\
\hline
\end{tabular}

2 patients in group A had diarrhea compared to 1 patient in group B. In group A, 6 patients experienced headache compared to 4 patients in group B. 1 patients in group B had flushing of face while in group A, no patients had this side effect. The difference was found to be statistically insignificant.

\section{Discussion}

Post-operative nausea and vomiting are the most common complaints after anaesthesia and surgery. PONV can contribute to the development of medical problems and patients with PONV consume more resources and require additional health care professional time compared with patients in whom these complications are avoided.

The overall incidence of PONV during the first 24 hours after surgery is approximately $30 \%$ with comparable variability. This incidence may be larger depending on preoperative patient characteristics, factors related to operation and anaesthesia, the intensity of pain and its management in the postoperative period ${ }^{[6]}$.

The mechanism of antiemetic action of corticosteroids is unknown, but may be related to inhibition of prostaglandin synthesis, decrease in $5-\mathrm{HT}_{3}$ level in the CNS and by an anti-inflammatory action at operative site ${ }^{[7]}$. Nucleus tractus solitarius in the medulla and Area Postrema are the main regions in which dexamethasone exerts its central antiemetic action. In conclusion, dexamethasone exerts its antiemetic action through activation of glucocorticoid receptors ${ }^{[8]}$.

In our study of group A, $46 \%$ patients experienced early nausea while $32 \%$ patients experienced delayed nausea. In group B, 20\% of patients had early as well as delayed nausea. Post-operative nausea was less in the combination group which is comparable to the study of V. Rajeeva et al. ${ }^{[9]}$. Fewer patients in combination group had late nausea similar to finding of Lopez et al. ${ }^{[10]}$, where only $8 \%$ of patients in combination group had delayed nausea as compared with $20 \%$ in the ondansetron group.

Our study did not correlate with that of Rusch D et al. ${ }^{\text {[11] }}$ whose study results found that the incidence of postoperative nausea did not differ much in the two high risk groups, $20 \%$ in the patients receiving ondansetron and $15 \%$ in patients receiving ondansetron and dexamethasone combination. Perhaps the difference in their study was due to inclusion of large number of subjects in their study and variability in surgeries conducted. Patients in our study groups experienced more nausea probably because of usage of fort win as premedication.

Our study regarding incidence of early vomiting in ondansetron group was $4 \%$ and delayed vomiting was $36 \%$. This is comparable to V. Rajeeva et al. ${ }^{[9]}$ study who had $15 \%$ early emesis and $35 \%$ delayed emesis after ondansetron. In the combination group of our study, the 
incidence of early vomiting was found to be $11 \%$ and delayed vomiting $3 \%$. This is also comparable to the study of V. Rajeeva et al. ${ }^{[9]}$, but does not agree with Lopez et $a l .{ }^{10}$, where no patient vomited in early period but $4 \%$ patients had vomiting episodes by 24 hours. In their study patients were undergoing major gynaecological surgery of longer duration than in our study, which may explain their results. It also did not correlate with the study of Rusch D et al. ${ }^{[11]}$ in which the incidence of postoperative vomiting was similar in both groups $11 \%$ in the ondansetron group and $7 \%$ in ondansetron plus dexamethasone group. This may be because their study was done in only high-risk groups and included a large number of patients.

Sanchez -Ledesma et al. ${ }^{[6]}$ in their study found out that a complete response defined as no nausea and no emetic episode occurred in $70 \%$ of patients who received ondansetron and dexamethasone which was comparable to our study where $76 \%$ of patients who received the combination showed a complete response.

In our study, $28 \%$ of patients in group A required rescue antiemetic compared to $4 \%$ of patients in group B and was statistically significant. This was comparable to the study conducted by Rusch et al. ${ }^{[27]}$ who showed that patients who were given combination of ondansetron and dexamethasone required less antiemetic. It also correlates with the study of Lopez-oleando et al. ${ }^{[10]}$ who showed that fewer patients in the combination group needed antiemetic rescue than patients treated with ondansetron alone.

The adverse effects, related to the use of combination therapy versus ondansetron alone did not reveal significance in our study. This was in accordance with the study of Rusch D et al. ${ }^{[11]}$ where it was found that the patients receiving ondansetron and dexamethasone combination had the same degree and number of adverse effects, as did those receiving only ondansetron. It also correlates with the study of Thomas $\mathrm{R}$ et al. ${ }^{[12]}$ whose study reported that most frequent adverse events were fatigue, headache, dizziness, but there was no differences between groups. Furthermore, study by Gan TJ et al. ${ }^{[13]}$ have found that adverse events have not been noted after a single bolus dose of dexamethasone.

Different studies have been done to control PONV with various combination therapy. The potential advantages of combination therapy using drugs that act on different pathways in the emetic response include improved efficacy, extended duration of the antiemetic effect, the ability to combine drugs with greater antinausea versus greater antiemetic effects and the possibility of using smaller of individual drugs compared with monotherapy ${ }^{[14]}$.

\section{Conclusion}

From our study we conclude that the combination therapy of injection ondansetron $4 \mathrm{mg}$ and injection dexamethasone 8 $\mathrm{mg}$ given intravenously just before induction is safe and more effective than injection ondansetron $4 \mathrm{mg}$ i.v. alone in reducing the incidence of early nausea and delayed nausea and vomiting and long term prevention of postoperative nausea and vomiting in patients undergoing elective surgeries under general anaesthesia. It can also be concluded that this combination therapy is safe with less adverse effects.

\section{Acknowledgment}

The authr thankful to Department of Anesthesiology, S.V.S Medical College \& Hospital for providing all the facilities to carry out this work.

\section{Conflict of interest}

None

\section{References}

1. Rose JB, Watcha MF. Postoperative nausea and vomiting in paediatric patients. Br J Anaesth. 1999; 83(1):104-117.

2. Patricia AK, Editorial. The big little problem. Anaesth Analg. 1991; 73:243-245.

3. Craigo $\mathrm{Pa}, \mathrm{Paul} \mathrm{A}$. Gastrointestinal physiology, aspiration of gastric content, postoperative nausea and vomiting. In: Collins VJ, edt., Physiologic and Pharmacologic bases of anaesthesia $1^{\text {st }}$ edn. Baltimore, Williams: Wilkins, 1996, 361-394.

4. Andrews PLR. Physiology of nausea and vomiting. Br J Anaesth. 1992; 69(S):24- 32.

5. Kenny GNC. Risk factors for post-operative nausea and vomiting. Anaesthesia. 1994; 49(S):6-10.

6. Sanchez-Ledesma MR, Lopez-Olaondo L, Pueyo FJ, Carrascosa F, Ortega A. A comparison of three antiemetic combinations for the prevention of postoperative nausea and vomiting. Anaesth Analg. 2002; 95:1590-1595.

7. Lee Y, Hsien-Young L, Pei-Chin L, Shen-Her H, YouSheng L. Dexamethasone prevents postoperative nausea and vomiting most effectively in women with motion sickness. Can J Anaesth. 2003; 50(3):232-237.

8. Ho CM, Ho ST, Wang JJ, Tsai SK, Chai CY. Dexamethasone has a central antiemetic mechanism in decerebrated cats. Anaesth Analg. 2004; 99:734-739.

9. Rajeeva V, Bharadwaj N, Bhatra YK, Dhaliwal LK. Comparison of ondansetron with ondansetron and dexamethasone in prevention of PONV in diagnostic laparoscopy. Can J Anaesth. 1999; 46(1):40-44.

10. Lopez-Olaondo L, Carrascosa F, Pueyo FJ, Mondero P, Busto M, Suez A. Combination of ondansetron and dexamethasone in the prophylaxis of postoperative nausea and vomiting. Br J Anaesth. 1996; 76:835-840.

11. Rusch D, Eberhart L, Biedler A, Dethling J, Apfel CC. Prospective application of a simplified risk score to prevent PONV. Can J Anaesth. 2005; 52:478-484.

12. Thomas R, Jones N. Prospective randomized, double blind comparative study of dexamethasone, ondansetron and ondansetron plus dexamethasone as prophylactic antiemetic therapy in patients undergoing day care gynaecological surgery. Br J Anaesth. 2001; 87(4):588-592.

13. Gan JT, Meyer T, Apfel CC, Chung F, Davis JP, Eubanks S. Consensus guidelines for management postoperative nausea and vomiting. Anaesth Analg. 2003; 97:62-71.

14. Gan JT, Coop A, Philip KB, Kytril study groups. A randomized, double blind study of granisetron plus dexamethasone versus ondansetron plus dexamethasone to prevent PONV in patients undergoing abdominal hysterectomy. Anaesth Analg. 2005; 101:1323-1329. 